\title{
Pulmonary artery pressure changes in the very low birthweight infant developing chronic lung disease
}

\author{
A B Gill, A M Weindling
}

\begin{abstract}
Pulmonary artery pressure may be estimated non-invasively in the premature newborn infant because of its negative correlation with the time to peak velocity:right ventricular ejection time (TPV:RVET) ratio calculated from the pulmonary artery Doppler waveform. We studied 54 very low birthweight infants on days $1,2,3,7,14,21$, and 28 after birth. Thirty four infants developed chronic lung disease (CLD). Twenty did not and acted as controls. After correcting the TPV:RVET ratio for heart rate (TPV:RVET(c)), during the first 14 days the TPV:RVET(c) ratio rose progressively in both groups suggesting a fall in pulmonary artery pressure. This occurred at a significantly slower rate in the CLD group. From days 14 to 28 there was a significant fall in the ratio in the CLD group only, suggesting an increase in pulmonary artery pressure. Using CLD as the end point, a TPV:RVET(c) ratio $<0.54$ on day 7 had a predictive value of $78 \%$ (sensitivity $73 \%$, specificity $65 \%$ ). This rose to a predictive value of $97 \%$ (sensitivity $88 \%$, specificity $95 \%$ ) on day 28 .

The non-invasive assessment of pulmonary artery pressure may be useful in the early clinical management of the very low birthweight infant at risk of developing CLD.
\end{abstract}

\section{(Arch Dis Child 1993;68:303-307)}

Chronic lung disease (CLD) is mainly confined to the very low birthweight infant, affecting approximately $40 \%$, and is a significant cause of morbidity and mortality in the first two years after birth. ${ }^{1-4}$ In infants with CLD, invasive measurements of pulmonary artery pressure after 6 months of age found that pulmonary hypertension was invariably present, and the degree of pulmonary hypertension correlated with subsequent morbidity and mortality. ${ }^{5-9}$ These observations are supported by postmortem studies on infants dying before 28 days of age. These have shown that the pulmonary vasculature has undergone changes consistent with an increase in pulmonary artery pressure. ${ }^{10-12}$

By using Doppler echocardiography it is possible to assess non-invasively pulmonary artery pressure. There are two principle methods available. The first is triscupid regurgitation and ductal velocity patterns. ${ }^{13} 14$ The advantage of tricuspid regurgitation and ductal velocity is that it is possible to obtain a quantitative estimate of pulmonary artery pressure. However, these measurements are technically quite difficult and are not possible in all ventilated preterm infants. The disappearance of tricuspid regurgitation and closure of the ductus arteriosus in the majority of infants by 10 days precludes these methods from use in more prolonged studies. By contrast, the second method, measurement of the time to peak velocity:right ventricular ejection time (TPV:RVET) ratio, ${ }^{15-18}$ is possible in all infants and is relatively straightforward to measure using a standard ultrasound machine and it allows an assessment of the changes in pulmonary artery pressure. Both methods have shown good correlation with invasive measurements of pulmonary artery pressures in older infants and children. ${ }^{19-22}$ Researchers using both methods showed that pulmonary artery pressure fell during the acute and early recovery phase of hyaline membrane disease. We are, however, unaware of any study that has been confined to the very low birthweight infant or where results have been correlated with the development of CLD.

The aims of this longitudinal study were twofold. Firstly, to study pulmonary artery pressure changes using the TPV:RVET ratio in very low birthweight infants with and without CLD. Secondly, to study the operating characteristics of this ratio as a means of identifying infants with CLD early in their postnatal course, potentially presenting a window of opportunity for therapeutic intervention.

\section{Patients and methods}

All infants were studied using an ATL Ultramark 4 scanner with a $5 \mathrm{MHz}$ range gated pulsed wave Doppler probe. Two dimensional imaging was performed with a 7.5 $\mathrm{MHz}$ probe. The pulmonary artery was visualised from the parasternal long axis view by rotating the probe and angling upwards until the right ventricular outflow tract, pulmonary valve, and main pulmonary artery were visualised. The sample volume of the range gated Doppler signal was placed distal to the pulmonary valve and the Doppler signal recorded (fig 1). A sweep speed of $100 \mathrm{~mm} / \mathrm{s}$ made it possible to identify individual Doppler waveforms. A minimum of five waveforms were recorded onto the system's computer module for off line analysis. Ductal patency and the direction of ductal flow was also assessed. 

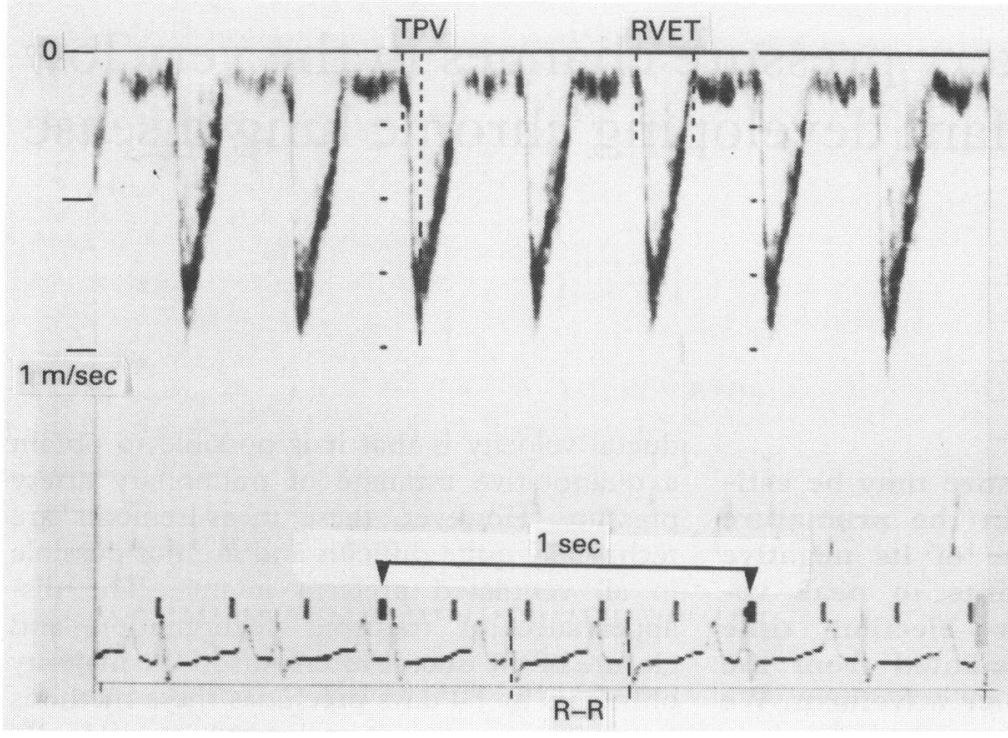

Figure 1 Doppler waveform from the main pulmonary artery. TPV (sec) and RVET (sec) shown on separate waveforms for clarity. $R-R=$ time difference between successive $R$ waves on the electrocardiogram (sec). TPV:RVET (c) calculated on five consecutive Doppler waveforms. $X$ axis represents time in seconds (time shown between two points). $Y$ axis represents Doppler shift in metres/sec (blood flow is away from the Doppler probe and, therefore, the Doppler trace is below the zero line).

Using the Doppler measurement system incorporated into the machine, the following time intervals were measured. TPV was measured from the onset of ejection to peak velocity; RVET was measured from the onset to the cessation of ejection ${ }^{15}$ (fig 1). The TPV:RVET ratio was corrected for heart rate by dividing by the square root of the $R-R$ interval (TPV:RVET(c)). ${ }^{22}$ Right ventricular function was assessed subjectively at each echocardiographic study.

Fifty four infants with birth weights below $1501 \mathrm{~g}$ were studied on days $1,2,3,7,14$, and 28 . The fractional inspired oxygen $\left(\mathrm{FiO}_{2}\right)$ requirement for positive pressure ventilation at the time of scan and the worst alveolar-arterial oxygen (a-A) ratio (a marker of the severity of hyaline membrane disease) on the first three days were recorded.

At 28 days of age, two groups of infants were identified and their TPV:RVET(c) ratios were compared:

(1) A group with CLD-these were infants who had been ventilated for hyaline membrane disease in the first 48 hours after birth and who were receiving supplemental oxygen at 28 days with characteristic radiographic appearances of CLD. ${ }^{23}$

Table 1 Demographic and clinical data for CLD and control groups

\begin{tabular}{lccrc}
\hline & $\begin{array}{l}C L D \\
(n=34)\end{array}$ & $\begin{array}{l}\text { Control } \\
(n=20)\end{array}$ & $\chi^{2}$ & $p$ Value \\
\hline $\begin{array}{l}\text { Media (range) birth weight } \\
\text { in g }\end{array}$ & $850(512-1452$ & $1214(814-1496)$ & & $<0.00001$ \\
$\begin{array}{l}\text { Median (range) gestation in } \\
\text { weeks }\end{array}$ & $\begin{array}{c}\text { 27 (23-31) } \\
\text { No (\%) receiving positive pressure ventilation: }\end{array}$ & $30(27-33)$ & & $<0.00001$ \\
Day 1 & $33(97)$ & $18(90)$ & & \\
Day 2 & $32(94)$ & $10(50)$ & $0 \cdot 2$ & NS \\
Day 3 & $32(94)$ & $7(58)$ & $13 \cdot 9$ & 0.0004 \\
Day 7 & $27(79)$ & $4(20)$ & $20 \cdot 1$ & 0.00001 \\
Day 14 & $21(62)$ & $1(5)$ & $15 \cdot 8$ & 0.00002 \\
Day 21 & $17(50)$ & $2(10)$ & 14.5 & 0.00004 \\
Day 28 & $13(38)$ & 0 & $7 \cdot 2$ & 0.003 \\
\hline
\end{tabular}

$\chi^{2}$ using Yates's correction

$\chi^{2}$ using Yates's correction.
NS=not significant at $5 \%$ level.
(2) A control group-infants who were not receiving supplemental oxygen or ventilatory support at 28 days.

Results are expressed as medians and the interquartile range. Comparison of data between groups was performed using the Mann-Whitney U test. Matched comparisons, within groups, from one day to another was using the Wilcoxon rank sum test. Correlations were performed using Spearman's non-parametric regression; $\chi^{2}$ (with Yates's correction) was used for analysis of numbers receiving positive pressure ventilation, ductal patency, and direction of ductal flow. The significance level was taken at $5 \%$.

A peak pulmonary artery pressure of $\leq 30$ $\mathrm{mm} \mathrm{Hg}$ is considered to represent the upper limit of normal pulmonary artery pressure. ${ }^{19-21}$ Previous studies have shown that the lower limit for the TPV:RVET in preterm infants is $0 \cdot 34 .{ }^{15-16}$ The average heart rate of preterm infants less than $1501 \mathrm{~g}$ is 155 (R-R interval $=0 \cdot 390) .{ }^{17}$ Therefore a TPV:RVET(c) of 0.54 probably represents the lower limit of pulmonary artery pressure in the preterm infant. Using CLD as the end point, we calculated the operating characteristics of a TPV:RVET(c) ratio $<0.54$ on each of the days of study.

The study was approved by the Liverpool Area Health Authority ethics committee and informed consent was obtained from the parents of each infant studied.

\section{Results}

There were 34 infants in the CLD group and 20 in the control group. Table 1 shows the demographic and clinical data for the two groups. Infants with CLD were of significantly lower birth weight and gestation when compared with the control group, $\mathrm{p}<0.0001$. The number of infants receiving positive pressure ventilation on each day of the study fell in both groups but there were significantly fewer ventilated infants in the control group from day 2 onwards.

Table 2 shows the a-A ratio and the $\mathrm{FiO}_{2}$ on the day of study. The a-A ratio was significantly lower in the CLD group over the first three days. It was not possible to calculate the a-A ratio after this time as many infants did not have regular arterial oxygen tension measurements by means of an indwelling arterial catheter. The $\mathrm{FiO}_{2}$ from day 1 was

Table 2 a-A oxygen ratio and $\mathrm{FIO}_{2}(\%)$ on the day of study in the CLD and control groups. All results are medians

\begin{tabular}{|c|c|c|c|c|}
\hline \multicolumn{2}{|c|}{$\begin{array}{l}\text { Day of } \\
\text { study }\end{array}$} & $\begin{array}{l}C L D \\
(n=34)\end{array}$ & $\begin{array}{l}\text { Control } \\
(n=20)\end{array}$ & p Value \\
\hline 1 & a-A ratio & $0 \cdot 16$ & $0 \cdot 29$ & $\begin{array}{l}0.02 \\
0.017\end{array}$ \\
\hline 2 & a-A ratio & $0 \cdot 16$ & $0 \cdot 22$ & 0.014 \\
\hline 3 & & $\begin{array}{l}50 \\
0 \cdot 18 \\
50\end{array}$ & & $\begin{array}{l}0.002 \\
0.0017 \\
0.0001\end{array}$ \\
\hline 7 & $\begin{array}{l}\mathrm{FIO}_{2} \\
\mathrm{FIO}_{2}\end{array}$ & $\begin{array}{l}50 \\
38\end{array}$ & $\begin{array}{l}25 \\
21\end{array}$ & $\begin{array}{l}0.0001 \\
<0.0001\end{array}$ \\
\hline 14 & $\mathrm{FIO}_{2}$ & 33 & 21 & $<0.0001$ \\
\hline 21 & $\mathrm{FIO}_{2}$ & 40 & 21 & $<0.0001$ \\
\hline 28 & $\mathrm{FIO}_{2}$ & 40 & 21 & $<0.0001$ \\
\hline
\end{tabular}

Analysis using Mann-Whitney U test; significance level 5\%. a-A ratio=alveolar-arterial oxygen difference. 


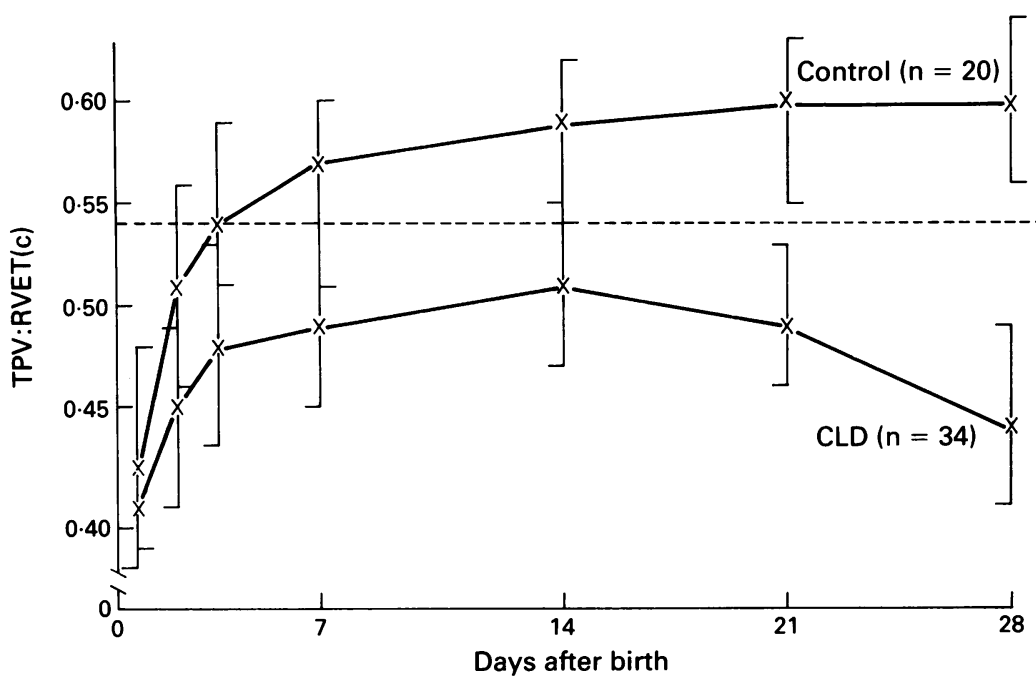

Figure 2 The TPV:RVET(c) ratio in CLD and control group by day of study. $X$ represents medians and closed bars interquartile range. Broken line represents lower limit of pulmonary artery pressure, TPV:RVET(c)=0.54 (corrected for heart rate).

Table 3 Doppler measurements of TPV (msec), RVET (msec), and heart rate (beats/minute) in the CLD and control groups on the day of study. All results are medians

\begin{tabular}{lllll}
\hline Day & of study & $\begin{array}{l}\text { CLD } \\
(n=34)\end{array}$ & $\begin{array}{l}\text { Control } \\
(n=20)\end{array}$ & $p$ Value \\
\hline \multirow{2}{*}{1} & TPV & 0.043 & 0.045 & NS \\
& RVET & 0.172 & 0.175 & NS \\
& Heart rate & 164 & 155 & NS \\
2 & TPV & 0.049 & 0.051 & NS \\
& RVET & 0.176 & 0.173 & NS \\
& Heart rate & 164 & 164 & NS \\
3 & TPV & 0.048 & 0.058 & 0.0009 \\
& RVET & 0.170 & 0.180 & NS \\
& Heart rate & 171 & 173 & NS \\
7 & TPV & 0.049 & 0.058 & 0.0007 \\
& RVET & 0.167 & 0.169 & NS \\
& Heart rate & 170 & 168 & NS \\
14 & TPV & 0.050 & 0.063 & 0.0005 \\
& RVET & 0.160 & 0.173 & NSD \\
& Heart rate & 168 & 164 & NS \\
21 & TPV & 0.050 & 0.062 & $<0.0001$ \\
& RVET & 0.170 & 0.180 & NS \\
& Heart rate & 166 & 164 & NS \\
28 & TPV & 0.048 & 0.069 & $<0.0001$ \\
& RVET & 0.170 & 0.176 & NS \\
& Heart rate & 168 & 162 & NS \\
\hline
\end{tabular}

Analysis using Mann-Whitney U test; significance level 5\%. Heart rate calculated from the $R-R$ interval on the electrocardiogram.

Table 4 Number (\%) of infants with patent ductus arteriosus and direction of ductal flow in CLD and control groups by day of study. Direction of flow expressed as the ratio of left-right:bidirectional

\begin{tabular}{|c|c|c|c|c|}
\hline \multirow[t]{2}{*}{ Day of study } & \multicolumn{2}{|c|}{$C L D(n=34)$} & \multicolumn{2}{|c|}{ Control $(n=20)$} \\
\hline & Patency & Direction & Patency & Direction \\
\hline 1 & $34(100)$ & $1: 2 \cdot 7^{*}$ & $20(100)$ & $1: 2 \cdot 3$ \\
\hline 2 & $25(74)$ & $1: 1 \cdot 3$ & $14(70)$ & $1: 1 \cdot 8$ \\
\hline 3 & $19(56)$ & $3 \cdot 8: 1$ & $8(40)$ & $3: 1$ \\
\hline 7 & $8(24)$ & $3: 1$ & $\dagger 2(10)$ & - \\
\hline 14 & $3(9)$ & $2: 1$ & $0-$ & - \\
\hline 21 & $2(6)$ & $1: 1$ & $0-$ & - \\
\hline 28 & $3(9)$ & $2: 1$ & $0-$ & - \\
\hline
\end{tabular}

* Two infants had pure right-left flow on day 1 only.

†Both infants had left-right flow.

Ratios only calculated on those with patent ducts.

Table 5 Operating characteristics of a TPV:RVET(c) ratio $<0.54$ in identifying infants with chronic lung disease by day of study

\begin{tabular}{llllllll}
\hline Day of study & 1 & 2 & 3 & 7 & 14 & 21 & 28 \\
\hline Sensitivity (\%) & 97 & 91 & 71 & 73 & 62 & 76 & 88 \\
Specificity (\%) & 15 & 40 & 60 & 65 & 80 & 85 & 95 \\
False positive rate (\%) & 85 & 60 & 40 & 35 & 20 & 15 & 5 \\
Predictive value (\%) & 66 & 72 & 75 & 78 & 84 & 89 & 97 \\
\hline
\end{tabular}

significantly lower in the control group, $\mathrm{p}=0 \cdot 017$. Between day 14 and day 28 , there was a rise in the $\mathrm{Fio}_{2}$ in the CLD group but this was not significant $(p=0 \cdot 36)$. There was a significant negative correlation between the $\mathrm{FIO}_{2}$ and TPV:RVET(c) from day 7 onwards, $r$ increasing from -0.54 on day $7(p<0.001)$ to -0.76 on day $28(p<0.0001)$.

Figure 2 shows the change in the TPV:RVET(c) ratio on days $1,2,3,7,14,21$, and 28. Both groups of infants showed a rise in the TPV:RVET(c) ratio over the first 14 days after birth. However the CLD group had a significantly lower ratio from day 2 onwards when compared with the control group, $p=0 \cdot 002$. The difference in the ratio was due to a shorter TPV from day 3 onwards, $\mathrm{p}=0.0009$ (table 3), rather than due to differences in RVET or heart rate. The CLD group had a significant fall in the TPV:RVET(c) ratio from days 14 to $28, p=0.0007$, whereas the ratio remained relatively constant in the control group, $p=0 \cdot 46$. There was no correlation between the TPV:RVET(c) ratio on day 1 and birth weight or gestation. Right ventricular function was considered to be normal in all infants throughout the study.

Table 4 shows the ductal patency and direction of ductal flow in both groups by day of study. Ductal patency fell from $100 \%$ on day 1 to $6 \%$ on day 28 . In both groups of infants bidirectional flow occurred in the majority on day 1 becoming mainly left-right flow by day 3. There were no significant differences in the duration of ductal patency or direction of ductal flow in the two groups by day of study. Of the three infants in the CLD group with patent ducts on day 28 , two underwent surgical ligation of the ductus arteriosus.

Table 5 shows the operating characteristics of a TPV:RVET(c) ratio $<0.54$ in predicting CLD on the days of study. There was a progressive rise in the predictive value from $65 \%$ on day 1 to $97 \%$ on day 28 . Other ratios $(0.49-0.56)$ were considered in a similar way, but the optimal operating characteristics were obtained from a ratio of $<0 \cdot 54$.

\section{Discussion}

Advances in neonatal intensive care have improved the survival of the very low birthweight infant but there has been an associated increase in the incidence of CLD. ${ }^{24}$ Pulmonary hypertension is invariably present in infants discharged home on supplemental oxygen $^{5-9}$ but until now the changes in pulmonary pressure have not been studied longitudinally in the very low birthweight infant during the first 28 days. From the limited data available it appears that pulmonary hypertension plays an important part in the pathophysiology of this condition $^{6}{ }^{10-11}$ and has been linked to the increased incidence of cot death in infants with CLD. ${ }^{4}$

The TPV:RVET ratio is influenced by pulmonary artery pressure, myocardial contractility, and heart rate. ${ }^{25}$ Our subjective 
assessment was that all infants had normal right ventricular function. The TPV, RVET and TPV:RVET are shortened as heart rate increases and therefore we corrected for this by dividing the ratio by the square root of the $\mathrm{R}-\mathrm{R}$ interval. ${ }^{22}{ }^{23} \mathrm{Kitabatake} e t{ }^{20}$ and Akibe et $a^{22}$ showed a close negative correlation between this ratio and directly measured pulmonary artery pressure in older infants and children. For the purposes of our study we considered that a peak pulmonary pressure of $30 \mathrm{~mm} \mathrm{Hg}$ represented the upper limit of normal pulmonary artery pressure. ${ }^{21}$ Using the regression equation quoted by Akibe et al this corresponds to a TPV:RVET(c) of 0.53 . The infants studied by Evans and Archer ${ }^{15-17}$ probably resemble our study population more closely, and from their results a TPV:RVET(c) of 0.54 being the lower limit of normal in the preterm infant. This figure was therefore chosen as the lower limit of normal pulmonary artery pressure. In fact, the operating characteristics were not significantly altered by using a figure of 0.53 .

We found that there was a progressive fall in pulmonary artery pressure in both groups of infants over the first 14 days. However the rate of decrease was slower in the CLD group. This is probably explained by the fact that they had more severe hyaline membrane disease than the control group as reflected by the significantly lower a-A ratio and higher $\mathrm{FrO}_{2}$ during the first three days. The median TPV:RVET(c) in the CLD group never reached the same level as the control group but, more importantly, significantly fell from days 14 to 28 suggesting a progressive rise in pulmonary artery pressure. The change in the direction of ductal flow over the first seven days probably occurred as a result of the fall in pulmonary artery pressure as evidenced by the rise in the TPV:RVET(c) over the same period. It appeared to have no bearing on the changes in the TPV:RVET(c) ratio from day 14 to day 28 .

The reason for the rise in pulmonary artery pressure is unclear but may be explained by the following pathological studies. Tomashefski et al ${ }^{11}$ found that in those infants with hyaline membrane disease who died during the first two weeks after birth, the pulmonary vascular tree showed changes consistent with adaptation to extrauterine life by thinning of the smooth muscle lining the pulmonary arterioles and remodelling of the pulmonary vasculature, but the changes were at a slower rate than in the term infant. After 4 weeks of age, Taghizadeh et $a l^{10}$ and Tomashefski et al ${ }^{11}$ found that in infants who developed CLD, there was significant muscularisation of the smaller pulmonary arterioles that progressively increased the longer CLD was present before death occurred. It was postulated that the changes in the pulmonary vasculature were secondary to persistent stimuli, such as hypoxia. From cardiac catheter data we know that hypoxia is a potent pulmonary vasoconstrictor and persistent hypoxic episodes will have a deleterious effect on the pulmonary vasculature. Our results appear to show that the normal cardiovascular adaptation to extrauterine life occurs in the very low birthweight infant over the first 14 days despite severe hyaline membrane disease. However, persistent impairment in lung function and parenchymal damage appears to reverse these changes leading to an increase in pulmonary artery pressure.

We also found that there was a progressive increase in the correlation between the TPV:RVET(c) and $\mathrm{FIO}_{2}$ from day 7 to day 28. This is in contrast to the observations of Evans and Archer who were unable to find any correlation, but in their study, infants were only studied if the $\mathrm{FIO}_{2}$ remained above $0 \cdot 5 .{ }^{17}$ However, our results showed an association between the pulmonary artery pressure and the severity of chronic lung disease. Invasive measurements in small groups of infants with CLD by Berman et al., ${ }^{7}$ Bush et $a l .,^{8}$ and Goodman et $a l^{9}$ also showed that raised pulmonary artery pressure was invariably present and correlated with the level of supplemental oxygen. In those studies failure to reduce pulmonary artery pressure after exposure to $100 \%$ oxygen was associated with a poor outcome. The importance of this is that it is more difficult to prevent hypoxic periods the higher the oxygen requirement. Recurrent hypoxia will have further deleterious effects on the pulmonary vasculature potentially leading to persistent pulmonary hypertension.

The second part to our study was to assess the operating characteristics of the TPV:RVET(c) ratio in identifying infants who were most likely to develop CLD early in their postnatal course. We found that if the TPV:RVET(c) was $<0.54$, we were able to predict CLD in the majority of patients (table 5) even by 7 days of age. The present management of infants with CLD is limited to supplemental oxygen, nutritional supplementation to increase growth and diuretics. ${ }^{324} \mathrm{By}$ estimating pulmonary artery pressure, using the TPV:RVET(c) ratio, infants at risk of developing CLD could be identified early in their postnatal course. This presents an opportunity for early therapeutic intervention. Interestingly, older infants with severe pulmonary hypertension secondary to CLD have been treated with calcium antagonists, such as nifedipine, in an attempt to reduce the pulmonary artery pressure. Brownlee et $a l^{26}$ and Johnson et $a l^{27}$ studied the clinical, pharmacokinetic, and pharmacodynamic short term effects of intravenous nifedipine on a small group of infants who had invasive measurements of pulmonary artery pressure. There was a significant short lived fall in pulmonary artery pressure and pulmonary vascular resistance and the pharmacology suggested first order kinetics. In addition to present therapeutic manoeuvres, we speculate that in order to influence CLD severity, treatment could be aimed at trying to prevent the rise in pulmonary artery pressure early in the postnatal course. This could be done either indirectly by attempting to minimise the parenchymal lung damage or directly by using 
pulmonary vasodilators. This might improve pulmonary perfusion, improve oxygenation, and break the cycle where hypoxia leads to further increases in vascular resistance.

Further studies are required to determine the extent to which this non-invasive assessment of pulmonary artery pressure can be used in the clinical management of the very low birthweight infant with CLD.

1 Horbar JD, Macauliffe TL, Adler SM, et al. Variability in 28-day outcomes for very low birth weight infants: analysis of 11 neonatal intensive care units. Pediatrics 1988;82:554-9.

2 Southall DP, Samules MP, Talbert DG. Recurrent cyanotic episodes with severe arterial hypoxaemia and intrapulmonary shunting: a mechanism for sudden death. Arch Dis Child 1990;65:953-61.

3 Southall DP, Samuels MP. Bronchopulmonary dysplasia: a new look at management. Arch Dis Child 1990; 65:1089-95.

4 Garg M, Kurzner SI, Bautistia DB, Keens TG. Clinically unsuspected hypoxia during sleep and feeding in infants with bronchopulmonary dysplasia. Pediatrics 1988;81: 653-92.

5 White MP, Houston AB. Pulmonary hypertension in bronchopulmonary dysplasia. Arch Dis Child 1990;65:1378.

6 Berman Jr W, Yabek SM, DIllon T, Burstein R, Corlew S. Evaluation of infants with bronchopulmonary dysplasia using cardiac catheterization. Pediatrics 1982;70:708-12.

7 Berman Jr W, Katz R, Yabek SM, Dillon T, Fripp RR, Papile L-A. Long term follow up of bronchopulmonary dysplasia. $\mathcal{F}$ Pediatr 1986;109:45-50.

8 Bush A, Busst CM, Knight WB, Hislop AA, Haworth SG, Shinebourne EA. Changes in pulmonary circulation in severe bronchopulmonary dysplasia. Arch Dis Child 1990;65:739-45.

9 Goodman G, Perkin RM, Anas NG, Sperling DR, Hicks DA, Rowen M. Pulmonary hypertension in infants with bronchopulmonary dysplasia. F Pediatr 1988;112:67-72.

10 Taghizadeh A, Reynolds EOR. Pathogenesis of bronchopulmonary dysplasia following hyaline membrane dischopulmonary dysplasia following

11 Tomashefski Jr JF, Opperman HC, Vawter GF, Reid LR. Bronchopulmonary dysplasia: a morphometric study with Bronchopulmonary dysplasia: a morphometric study with emphasis on

12 Rudolph AM. High pulmonary vascular resistance after birth: 1. Pathophysiologic considerations and etiologic classification. Clin Pediatr (Phila) 19:585-90.
13 Skinner JR, Boys JR, Hunter S, Hey EN. Non-invasive assessment of pulmonary arterial pressure in healthy neonates. Arch Dis Child 1990;66:386-90.

14 Skinner JR, Boys Hunter S, Hey EN. Pulmonary and systemic arterial pressure in hyaline membrane disease. Arch Dis Child 1992;67:366-73.

15 Evans NJ, Archer LNJ. Postnatal circulatory adaptation in healthy term and preterm infants. Arch Dis Child 1990;65:24-6.

16 Evans NJ, Archer LNJ. Doppler assessment of pulmonary artery pressure and extrapulmonary shunting in the acute phase of hyaline membrane disease. Arch Dis Child 1991;66:6-11.

17 Evans NJ, Archer LNJ. Doppler assessment of pulmonary artery pressure during recovery from hyaline membrane disease. Arch Dis Child 1991;66:802-4.

18 Evans NJ, Archer LNJ. Non-invasive assessment of pulmonary arterial pressure in healthy neonates. Arch Dis Child 1991;66:1100.

19 Martin-Duran R, Larman M, Trugeda A, et al. Comparison of Doppler-determined elevated pulmonary arterial pressure with pressure measured at cardiac catheterization. Am $\mathcal{f}$ Cardiol 1986;57:859-63.

20 Kitabatake A, Inoue M, Asao M, et al. Non-invasive evaluation of pulmonary hypertension by a pulsed Doppler technique. Circulation 1983;68:302-9.

21 Kosturakis D, Goldberg SJ, Allen HA, Loeber C. Doppler echocardiographic prediction of pulmonary hypertension in congenital heart disease. Am 7 Cardiol 1984.53: $1110-5$.

22 Akibe T, Yoshikawa M, Otaki S, Kobayashi Y, Nakasato $M$, Suzuki $H$. Prediction of pulmonary artery pressure by $\mathrm{M}$, Suzuki H. Prediction of pulmonary artery pressure by continuous-wave Doppler echocardiograp

23 Northway Jr WM, Rosan RC, Porter DY. Pulmonary disease following respirator therapy of hyaline-membrane disease: bronchopulmonary dysplasia. $N \mathrm{Engl} f \mathrm{Med}$ 1967;276:357-68

24 Northway Jr H. Bronchopulmonary dysplasia: then and now. Arch Dis Child 1990;65:1076-81.

25 Serwer GA, Cougle AG, Eckerd JM, Armstrong BE. Factors affecting use of the Doppler-determined time from flow onset to maximum pulmonary artery velocity for measurement of pulmonary artery pressure in children. Am f Cardiol 1986;58:352-6.

26 Brownlee JR, Beekman RH, Rosenthal A. Acute haemodynamic effects of nifedipine in infants with bronchopulmonary dysplasia and

27 Johnson CE, Beekman RH, Kostyshak DA, Nguyen T, Oh D, Amidon GL. Pharmocokinetics and pharmacodynamics of nifedipine in children with bronchopulmonary dysplasia and pulmonary hypertension. Pediatr Res 1991;29:500-3. 